\title{
Successful vaccination against Leishmania chagasi infection in BALB/c mice with freeze-thawed Leishmania antigen and Corynebacterium parvum
}

\author{
Márcia de Carvalho Vilela ${ }^{a}$, Daniel Cláudio de Oliveira Gomes ${ }^{b}$, \\ Eduardo de Almeida Marques-da-Silva ${ }^{a}$, Tiago Donatelli Serafim ${ }^{\mathrm{a}}$, \\ Luis Carlos Crocco Afonso ${ }^{a}$, Simone Aparecida Rezende ${ }^{\mathrm{a}, \mathrm{c}, *}$ \\ a Laboratório de Imunoparasitologia, DECBI/NUPEB, Campus Universitário, Morro do Cruzeiro, \\ Universidade Federal de Ouro Preto, Cep: 35.400-000, Ouro Preto, MG, Brazil \\ ${ }^{\mathrm{b}}$ Instituto de Biofísica Carlos Chagas Filho/UFRJ, Brazil

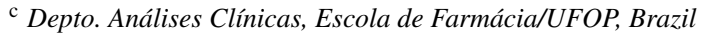

Received 16 April 2007; received in revised form 9 July 2007; accepted 28 August 2007

Available online 31 August 2007

\begin{abstract}
This study evaluated the potential of a Leishmania antigen vaccine in protecting BALB/c mice against Leishmania chagasi. Mice received two subcutaneous doses of L. amazonensis vaccine with Corynebacterium parvum and subsequent boost was done without adjuvant. One week later, mice were challenged with $L$. chagasi. We observed that this vaccine caused a significant reduction in parasite load in liver and spleen and induced a high production of IFN- $\gamma$ and IL- 4 by spleen cells from vaccinated mice in response to Leishmania antigen. Together, our data show that this vaccine is capable of inducing a Th1/Th2 response that is important to control parasite replication.
\end{abstract}

(C) 2007 Elsevier B.V. All rights reserved.

Keywords: Vaccine; Leishmania chagasi; Mice; IFN- $\gamma$; IL-4

\section{Introduction}

Leishmaniasis is a spectrum of diseases caused by infection with different species of the protozoan Leishmania. These diseases range from self-limiting cutaneous leishmaniasis to visceral leishmaniasis, also known as kalazar, which if a fatal infection if not treated

\footnotetext{
* Corresponding author at: Laboratório de Imunoparasitologia, DECBI/NUPEB, Campus Universitário, Morro do Cruzeiro, Universidade Federal de Ouro Preto, Cep: 35.400-000, Ouro Preto, MG, Brazil. Tel.: +55 313559 1702; fax: +55 3135591680 .

E-mail address: rezende@nupeb.ufop.br (S.A. Rezende).
}

successfully. Human infection with Leishmania chagasi, the protozoan causing South American visceral leishmaniasis, causes diverse sequel ranging from sub-clinical infection to progressive fatal disease (Wilson, 1993). Sub-clinical infection results in the development of a cellular immune response that often results in longterm protective immunity against re-infection (Pearson and Sousa, 1996). A goal of anti-leishmanial vaccine development is to replicate this naturally acquired protective immunity through immunization with parasite antigens.

The involvement of T helper 1 (Th1) and T helper 2 (Th2) subsets with protection and disease exacerba- 
tion, respectively, has been demonstrated in the murine model of cutaneous leishmaniasis caused by L. major (Heinzel et al., 1989). In contrast, a similar pattern of T-helper cell subsets has not been demonstrated in visceral leishmaniasis. Wilson and Weinstock (1996) have shown that IFN- $\gamma$ is critical for cure of visceral leishmaniasis in mice. Liver granuloma cells obtained from $\mathrm{C} 3 \mathrm{H} . \mathrm{HeJ}$ mice, that show a low parasite burden in liver, produce high levels of IFN- $\gamma$. Otherwise, cells obtained from BALB/c mice, that are susceptible to infection with L. chagasi, produce no IFN- $\gamma$. Afterwards, (Wilson et al., 1998) showed that liver granuloma cells produce TGF$\beta$ and this cytokine is responsible for the inhibition of IFN- $\gamma$ production. Furthermore, the production of IL- 4 is important for granuloma maturation (Stager et al., 2003), protection induced by vaccine (Ghosh et al., 2001) and for cure associated with chemotherapy (Alexander et al., 2000).

In this study, we evaluated the potential of a freezethawed Leishmania antigen vaccine (composed of PH8 strain of $L$. amazonensis) as a vaccine candidate against L. chagasi infection. This vaccine was developed in 1979 (Mayrink et al., 1979) and has been used not only in the prevention of the disease (Nascimento et al., 1990) but also as an immunotherapeutic agent in cases where antimonium salts cannot be used (Hermeto et al., 1994). Cross-species protection has been documented in other studies in leishmaniasis (Gicheru et al., 1997, Misra et al., 2001). These findings tempted us to investigate if subcutaneous immunization with a Leishmania amazonensis vaccine in conjunction with $C$. parvum was able to protect $\mathrm{BALB} / \mathrm{c}$ mice against $L$. chagasi infection.

\section{Materials and methods}

\subsection{Leishmania parasites and antigen}

The strain of $L$. chagasi used in this study was kindly provided by Dr. Maria Norma de Melo, Dep. de Parasitologia, UFMG, Belo Horizonte. Promastigotes were grown in DMEM pH 6,8 supplemented with $20 \%$ heat-inactivated fetal bovine serum (FBS), $2 \mathrm{mM}$ L-glutamine, $25 \mathrm{mM}$ HEPES, $50 \mu \mathrm{M}$ 2-mercaptoetanol and $20 \mu \mathrm{g} / \mathrm{mL}$ garamicin (DMEM $20 \% \mathrm{FBS}$ ) at $25^{\circ} \mathrm{C}$. Parasites used in this study were maintained up to 15 passages in culture. Infectivity was maintained by serial passage through mice. L. amazonensis was grown in Grace's Medium (Grace's medium supplemented with $20 \%$ FBS, $2 \mathrm{mM} \mathrm{L}$-glutamine and $20 \mu \mathrm{g} / \mathrm{mL}$ garamicin). For mice inoculation and vaccine preparation promastigotes from L. chagasi or L. amazonensis were harvested from late-log-phase cultures by centrifugation, washed three times with PBS and disrupted by three rounds of freezing and thawing. The protein content was estimated by the Lowry method (Lowry et al., 1951) and the antigen was frozen at $-70{ }^{\circ} \mathrm{C}$ until use.

\subsection{Mice and vaccine}

Female BALB/c mice (4-6 weeks old) were obtained from CEBIO, UFMG, Belo Horizonte and were maintained at Biotério Central/UFOP. The vaccine used in this study was produced with one strain of Leishmania amazonensis (IFLA/BR/67/PH8). Promastigotes of L. amazonensis were harvested as described previously. Vaccine was prepared with a concentration of $800 \mu \mathrm{g}$ of protein $/ \mathrm{mL}$ and $0.01 \%$ merthiolate. This vaccine was kindly provided by Dr Wilson Mayrink, Departamento de Parasitologia, UFMG, Belo Horizonte.

$\mathrm{BALB} / \mathrm{c}$ mice were immunized with two subcutaneous doses ( 2 weeks apart) of $100 \mu \mathrm{g}$ of L. amazonensis vaccine along with $250 \mu \mathrm{g}$ of Corynebacterium parvum and subsequent boost was done 4 weeks later with $10 \mu \mathrm{g}$ of $L$. amazonensis vaccine without adjuvant. Injections were given at the tail base. Control mice were inoculated with PBS without adjuvant. One week later, mice were challenged with $1 \times 10^{7}$ promastigotes of $L$. chagasi given intravenously by lateral tail vein. Two, 4 and 6 weeks later, mice were sacrificed and spleen and liver parasite load was determined by quantitative limitingdilution culture with some modifications (Titus et al., 1985).

\subsection{Determination of vaccine-induced cytokine production}

Spleen and liver from PBS-inoculated and vaccinated mice were harvested and their weight was determined. One fragment of each organ was obtained and weighed separately for parasite quantification. Single cell suspensions of spleen were obtained by tissue grinder homogenization. The erythrocytes were lysed with ammonium chloride lysis buffer and the cells were washed and cultured in DMEM pH 7,2 supplemented with $10 \%$ heat-inactivated fetal bovine serum, $2 \mathrm{mM}$ L-glutamine, $25 \mathrm{mM}$ HEPES, $50 \mu \mathrm{M}$ 2-mercaptoetanol and $20 \mu \mathrm{g} / \mathrm{mL}$ garamicin (DMEM 10\% SFB) at $5 \times 10^{6}$ cells $/ \mathrm{mL}$. These cells were cultured in 96-well flatbottom microtiter plates in medium alone (control) or stimulated with $50 \mu \mathrm{g}$ of $L$. chagasi or L. amazonensis $\mathrm{Ag} / \mathrm{mL}$ of culture for $72 \mathrm{~h}$. The production of IFN- $\gamma$ and IL-4 was determined in cell culture supernant by ELISA (Afonso and Scott, 1993). 


\subsection{Determination of the tissue parasite burden}

Quantitative limiting-dilution culture was performed as described previously with some modifications (Titus et al., 1985). A weighed piece of each organ (liver and spleen) was homogenized in tissue grinder and re-suspended in $500 \mu \mathrm{L}$ of DMEM $20 \%$ FBS in 48-well flat-bottom microtiter plates. Fivefold serial dilution was done and after 2 weeks the plates were scored microscopically for parasite growth. The number of parasites was determined from the reciprocal of the highest dilution at which promastigotes could be detected at 2 weeks of incubation at $25^{\circ} \mathrm{C}$ and was expressed as parasites per organ.

\subsection{Statistical analysis}

All data were analyzed by Kolmogorov-Smirnov normality test. All data were not considered normal and were submitted to non-parametric Mann-Whitney's test.

\section{Results}

\subsection{IFN- $\gamma$ and IL-4 production by splenocytes 3 days after challenge}

Initially, we determined whether immunization of mice with a $L$. amazonensis vaccine was able to induce cytokines that were protective against infection with $L$. chagasi. Mice were immunized with this vaccine and, 1 week later, they were challenged with $1 \times 10^{7} \mathrm{~L}$. chagasi promastigotes. Three days after infection, spleen cells from PBS-inoculated and vaccinated mice were obtained and stimulated with L. chagasi or L. amazonensis antigen. Higher levels of IFN- $\gamma$ were produced 3 days after challenge by PBS-inoculated and vaccinated mice cells in response to $L$. chagasi and $L$. amazonensis antigen when compared to non-stimulated cells (Fig. 1A). However, there was no difference in the level of IFN- $\gamma$ between spleen cells obtained from PBS-inoculated and vaccinated mice stimulated with Leishmania antigen. Spleen cells from vaccinated mice produced a higher level of IL-4 when stimulated with both antigens when compared non-stimulated cells. Furthermore, spleen cells obtained from vaccinated mice produced a higher level of IL-4 in response to both antigens when compared with cells obtained from PBS-inoculated mice (Fig. 1B).

\subsection{IFN- $\gamma$ and IL-4 production by spleen cells at 2 , 4 and 6 weeks after challenge}

We also evaluated IFN- $\gamma$ and IL-4 production by spleen cells from PBS-inoculated and vaccinated mice
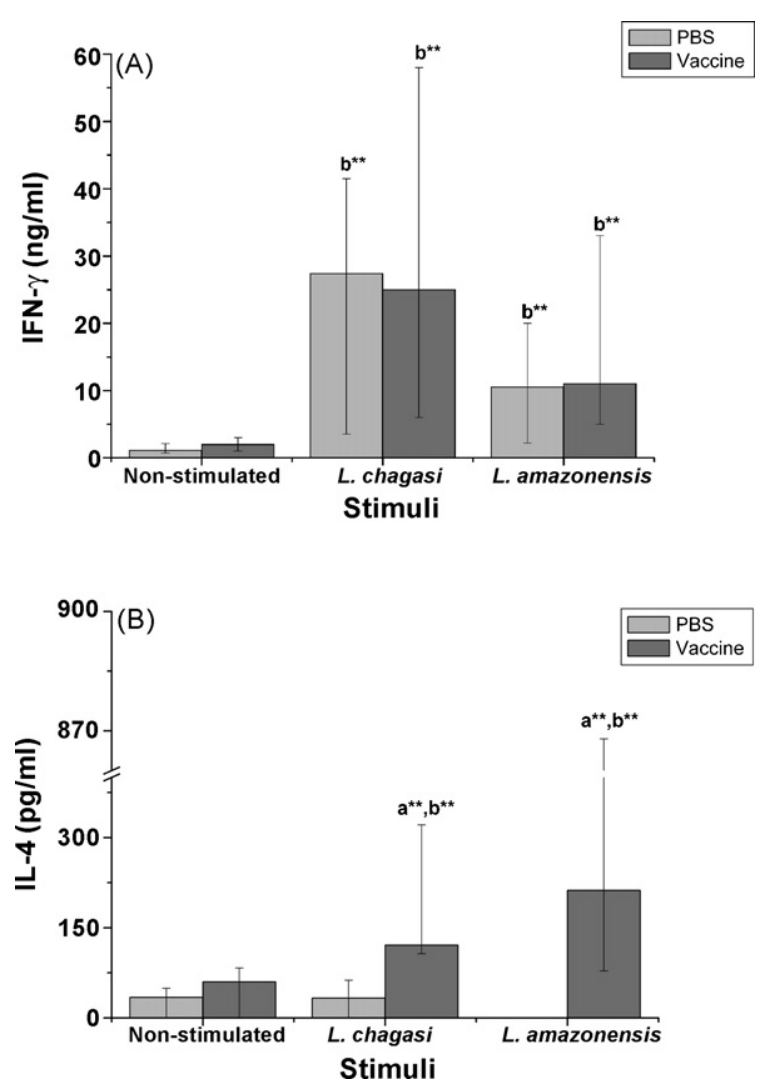

Fig. 1. IFN- $\gamma$ (A) and IL-4 (B) production by splenocytes 3 days after challenge. BALB/c mice were immunized with Leishmania amazonensis $+C$. parvum or with PBS as a control. One week later, mice were challenged with $L$. chagasi. Three days later, mice were killed and spleen was collected. Splenocytes were stimulated with $L$. chagasi or L. amazonensis Ag and 3 days later supernatants were collected and cytokine level was determined by ELISA. These results are represented as the median $\pm 25 \%$ of data distribution from two to four experiments with four to six mice. Letter over the bars represent significant IFN- $\gamma$ production by spleen cells in the following comparisons: (a): vaccinated $\times$ PBS-inoculated, (b): Ag stimulated $\times$ non-stimulated. Statistical differences between cytokine production by stimulated cells and their respective non-stimulated control were determined by nonparametric Mann-Whitney's test $(* * p<0.01)$.

2, 4 and 6 weeks after challenge. In all weeks evaluated, it was observed a higher IFN- $\gamma$ production by spleen cells from vaccinated mice in response to both antigens when compared to IFN- $\gamma$ production by cells from PBS-inoculated mice, with one exception - spleen cells obtained from mice with 6 weeks of infection stimulated with L. chagasi Ag (Fig. 2A). We also observed that this vaccine was able to induce a higher production of IL-4 in all weeks studied when spleen cells were stimulated with $L$. chagasi or L. amazonensis Ag. This increase was much more pronounced than the one observed with IFN- $\gamma$, mainly because spleen cells obtained from PBS- 

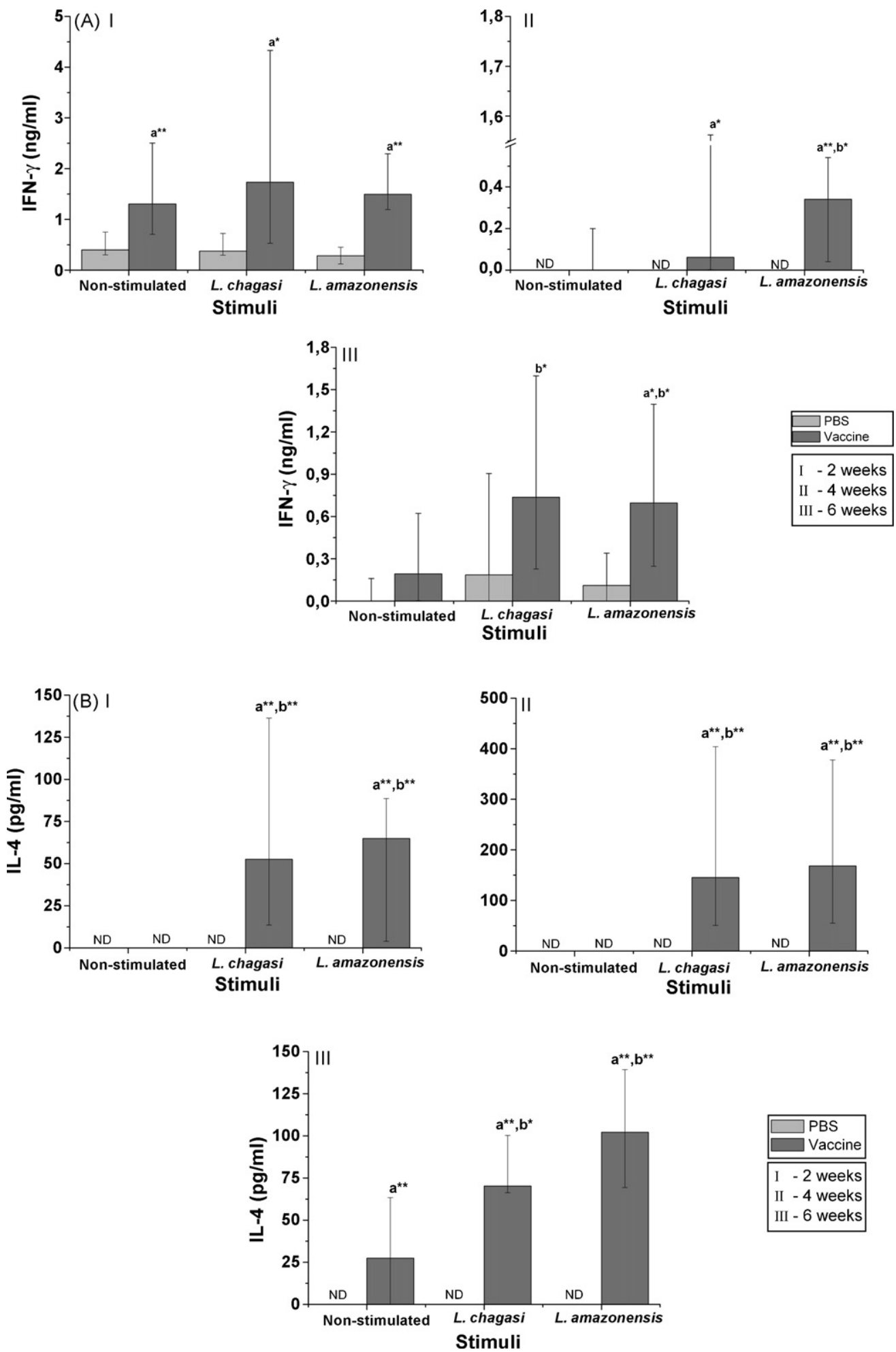

Fig. 2. IFN- $\gamma$ (A) and IL-4 (B) production by splenocytes in different weeks after challenge in PBS-inoculated and vaccinated mice. BALB/c mice were immunized with Leishmania amazonensis $+C$. parvum or with PBS as a control. One week later, mice were challenged with $L$. chagasi. 2, 4 or 6 weeks later, mice were killed and spleen was collected. Splenocytes were stimulated with L. chagasi or L. amazonensis Ag and 3 days later supernatants were collected and cytokine level was determined by ELISA. These results are represented as the median and $25 \%$ of data 
inoculated mice did not produce IL-4 in response to Leishmania antigen.

\subsection{Parasite load in liver and spleen}

In order to determine if $L$. amazonensis $\mathrm{Ag}$ vaccine was able to protect BALB/c mice from $L$. chagasi infection, we evaluated parasite load in liver and spleen by limiting-dilution analysis. We evaluated the magnitude of parasite load in vaccinated and PBS-inoculated mice in different times after intravenous challenge with $1 \times 10^{7}$ parasites. A significant reduction in parasite load was observed both in liver at 2, 4 and 6 weeks of infection (Fig. 3A) and in spleen, at 2 weeks of infection (Fig. 3B) from immunized mice when compared to PBSinoculated mice. Thus, this vaccine (composed of PH8 strain of $L$. amazonensis) was able to provide a partial protection in BALB/c mice infected with Leishmania chagasi associated with a mixed $\mathrm{Th} 1 / \mathrm{Th} 2$ response.

\section{Discussion}

Leishmaniasis has always been one of the promising diseases for vaccine development, since it has been known that exposure and cure from infection usually results in long lasting immunity (Pearson and Sousa, 1996). Although some works have tried vaccination with live parasites (Streit et al., 2001), there are ethical considerations against live parasite vaccine and attention has shifted to killed parasite vaccines.

A vaccine against cutaneous leishmaniais was developed by Mayrink et al. (1979) and was prepared from 5 stocks of parasites isolated from patients with different forms of leishmaniasis. Subsequently, it was developed another vaccine that used only PH8 strain of Leishmania amazonensis. This vaccine was licenced in 1999 by Brazil Healthy Minister for use in therapy and it was commercialized as Leishvacin. Since then, the vaccine has been used as an immunotherapeutic agent in cases where antimonium salts cannot be used. In this manner, it was shown that combining therapy was able to reduce the time necessary for complete healing of the lesions when compared to conventional therapy (Toledo et al., 2001).

During this study, we evaluated if this vaccine was able to provide heterologous protection against $L$. chagasi infection in BALB/c mice. Cross-species protection
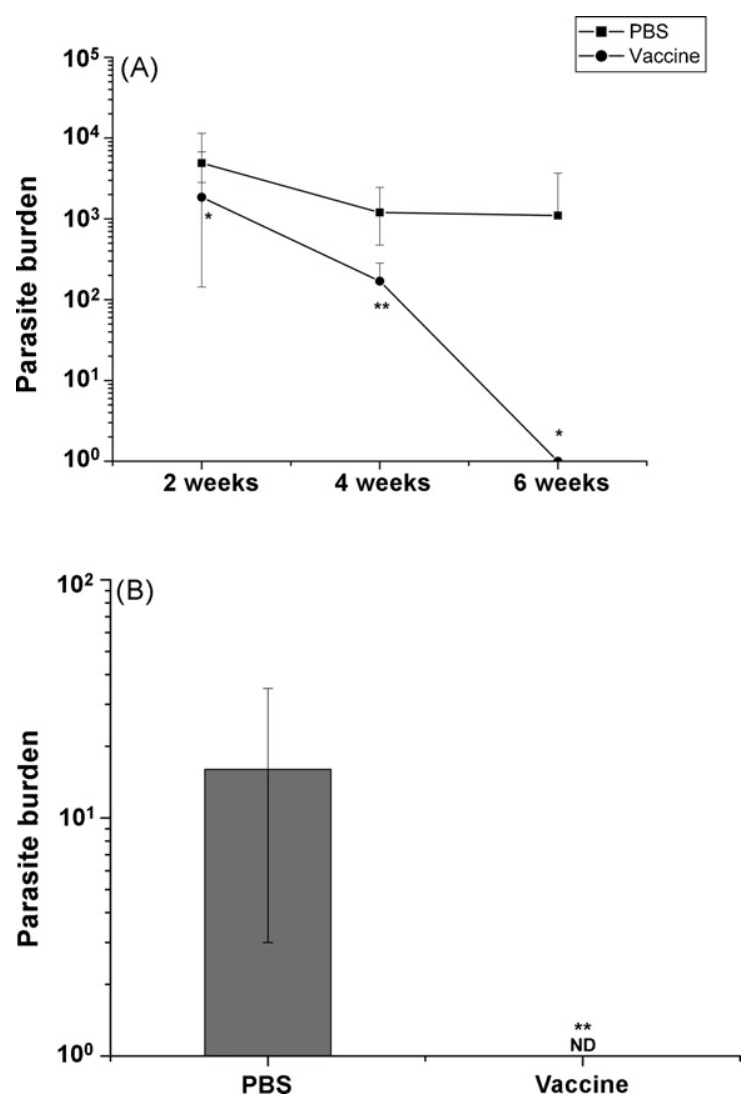

Fig. 3. Liver (A) and spleen (B) parasite burden from vaccinated $\mathrm{BALB} / \mathrm{c}$ mice challenged 1 week after booster. BALB/c mice were vaccinated, as described in Section 2, and challenged by intravenous route with $1 \times 10^{7} \mathrm{~L}$. chagasi late-log-phase promastigotes 1 week after booster. Two, four and six weeks after challenge, mice were sacrificed and their liver and spleen were harvested for parasite quantification by limiting-dilution culture. Results are represented as the median and $25 \%$ of data distribution from two to four experiments with four to six mice. Statistical differences in parasite load between vaccinated and PBS-inoculated mice were determined by non-parametric Mann-Whitney's test $\left({ }^{*} p<0.05 ; * *<0.01\right)$.

has been documented in other studies in leishmaniasis. Gicheru et al. (1997) demonstrated that Vervet monkeys that had been previously infected with Leishmania donovani were protected against $L$. major infection. Furthermore, Misra et al. (2001) showed that alumprecipitated autoclaved Leishmania major along with BCG protected monkeys against Leishmania donovani infection. In this study, mice were vaccinated $L$. amazonensis vaccine and we observed that this vaccine was able to reduce parasite load in the liver $(2,4$ and 6 weeks

distribution from two to four experiments with four to six mice. Letter over the bars represent significant IFN- $\gamma$ production by spleen cells in the following comparisons: (a): vaccinated $\times$ PBS-inoculated, (b): Ag stimulated $\times$ non-stimulated. Statistical differences between cytokine production by stimulated cells and their respective non-stimulated control were determined by non-parametric Mann-Whitney's test $(* p<0.05 ; * * p<0.01)$. IL-4 production was not detected by spleen cells obtained from PBS-inoculated mice. ND: not detectable. 
of infection) and spleen (2 weeks of infection). These data suggest that different mechanisms are involved in the protection in these organs, since at 4 and 6 weeks of infection, protection was observed only in the liver.

Furthermore, we evaluated the production of IFN- $\gamma$ and IL- 4 by spleen cells stimulated with Leishmania Ag and the parasite load in both liver and spleen. Cytokine evaluation was done initially 3 days after challenge and it was observed a higher production of IFN- $\gamma$ by spleen cells in response to both antigens by PBS-inoculated and vaccinated mice in comparison to non-stimulated cells. We believe that this rapid production of IFN- $\gamma$ is due the cross-reaction among Leishmania and microbial $\mathrm{Ag}$ found in the flora. One of these antigens, Leishmania homologue of mammalian RACK (LACK) is able to induce a rapid production of IL- 4 by $\mathrm{V} \beta 4 \mathrm{~V} \alpha 8$ $\mathrm{CD}^{+} \mathrm{T}$ cells in the draining lymph nodes within $16 \mathrm{~h}$ after the subcutaneous infection of $L$. major promastigotes (Mougneau et al., 1995). Furthermore, there was no increase in the production of IFN- $\gamma$ by spleen cells obtained from vaccinated mice as compared to PBSinoculated mice. Otherwise, the level of IL-4 was higher by spleen cells from vaccinated mice as compared to PBS-inoculated mice when these cells were stimulated with Leishmania Ag.

Cytokine evaluation was done also 2, 4 and 6 weeks after infection and we observed that $L$. amazonensis vaccine was able to induce a significant production of IFN- $\gamma$ by spleen cells from vaccinated mice when compared to spleen cells from mice inoculated with PBS. Furthermore, a much more pronounced increase was observed in the level of IL-4. Many studies have shown that this cytokine is important in visceral model of leishmaniasis. Stager et al. (2003) have shown that IL-4 (and IL-13) is important for granuloma maturation and antileishmanial activity in the murine model of $L$. donovani infection. Furthermore, some studies have shown that protection induced by vaccines against $L$. donovani and L. infantum/chagasi is associated with a mixed Th1/Th2 pattern. Ghosh et al. (2001) showed that immunization with A2 protein protects mice against $L$. donovani infection and this protein induces a mixed Th1/Th2 and a humoral response. Ramiro et al. (2003) showed that LACK immunization in a heterologous prime-boost regime (plasmid DNA and recombinant vector) was able to protect dogs against $L$. infantum infection, and this protection was associated with an increase in the mRNA level of IL-4 and IFN- $\gamma$ in peripheral blood mononuclear cells.

Thus, this study shows that a vaccine composed of L. amazonensis is able to protect $\mathrm{BALB} / \mathrm{c}$ mice against an endovenous challenge with $L$. chagasi promastigotes and this protection is associated with the induction of both IFN- $\gamma$ and IL-4. Furthermore, it shows that crossprotection between Leishmania species presents a major practical implication, and that this vaccine can be part of a vaccination scheme that offers protection against $L$. chagasi in the mouse model of visceral leishmaniasis.

\section{References}

Afonso, L.C., Scott, P., 1993. Immune responses associated with susceptibility of C57BL/10 mice to Leishmania amazonensis. Infect. Immun. 61, 2952-2959.

Alexander, J., Carter, K.C., Al-Fasi, N., Satoskar, A., Brombacher, F., 2000. Endogenous IL-4 is necessary for effective drug therapy against visceral leishmaniasis. Eur. J. Immunol. 30, 2935-2943.

Ghosh, A., Zhang, W.W., Matlashewski, G., 2001. Immunization with A2 protein results in a mixed $\mathrm{Th} 1 / \mathrm{Th} 2$ and a humoral response which protects mice against Leishmania donovani infections. Vaccine 20, 59-66.

Gicheru, M.M., Olobo, J.O., Anjili, C.O., 1997. Heterologous protection by Leishmania donovani for Leishmania major infections in the vervet monkey model of the disease. Exp. Parasitol. 85, $109-116$.

Heinzel, F.P., Sadick, M.D., Holaday, B.J., Coffman, R.L., Locksley, R.M., 1989. Reciprocal expression of interferon gamma or interleukin 4 during the resolution or progression of murine leishmaniasis. Evidence for expansion of distinct helper T cell subsets. J. Exp. Med. 169, 59-72.

Hermeto, M.V., Vieira-Dias, D., Genaro, O., Rotondo-Silva, A., Da Costa, C.A., Toledo, V.P., Michalick, M.S., Williams, P., Mayrink, W., 1994. Outbreak of cutaneous leishmaniasis in the Rio Doce Valley, Minas Gerais, Brazil. Mem. Inst. Oswaldo Cruz 89, 519-521.

Lowry, O.H., Rosebrough, N.J., Farr, A.L., Randall, R.J., 1951. Protein measurement with the Folin phenol reagent. J. Biol. Chem. 193, 265-275.

Mayrink, W., Da Costa, C.A., Magalhaes, P.A., Melo, M.N., Dias, M., Lima, A.O., Michalick, M.S., Williams, P., 1979. A field trial of a vaccine against American dermal leishmaniasis. Trans. R. Soc. Trop. Med. Hyg. 73, 385-387.

Misra, A., Dube, A., Srivastava, B., Sharma, P., Srivastava, J.K., Katiyar, J.C., Naik, S., 2001. Successful vaccination against Leishmania donovani infection in Indian langur using alum-precipitated autoclaved Leishmania major with BCG. Vaccine 19, 3485-3492.

Mougneau, E., Altare, F., Wakil, A.E., Zheng, S., Coppola, T., Wang, Z.E., Waldmann, R., Locksley, R.M., Glaichenhaus, N., 1995. Expression cloning of a protective Leishmania antigen. Science 268, 563-566.

Nascimento, E., Mayrink, W., Da Costa, C.A., Michalick, M.S., Melo, M.N., Barros, G.C., Dias, M., Antunes, C.M., Lima, M.S., Taboada, D.C., 1990. Vaccination of humans against cutaneous leishmaniasis: cellular and humoral immune responses. Infect. Immun. 58, 2198-2203.

Pearson, R.D., Sousa, A.Q., 1996. Clinical spectrum of Leishmaniasis. Clin. Infect. Dis. 22, 1-13.

Ramiro, M.J., Zarate, J.J., Hanke, T., Rodriguez, D., Rodriguez, J.R., Esteban, M., Lucientes, J., Castillo, J.A., Larraga, V., 2003. Protection in dogs against visceral leishmaniasis caused by Leishmania infantum is achieved by immunization with a heterologous prime-boost regime using DNA and vaccinia recombinant vectors expressing LACK. Vaccine 21, 2474-2484. 
Stager, S., Alexander, J., Carter, K.C., Brombacher, F., Kaye, P.M., 2003. Both interleukin-4 (IL-4) and IL-4 receptor alpha signaling contribute to the development of hepatic granulomas with optimal antileishmanial activity. Infect. Immun. 71, 48044807.

Streit, J.A., Recker, T.J., Filho, F.G., Beverley, S.M., Wilson, M.E., 2001. Protective immunity against the protozoan Leishmania chagasi is induced by subclinical cutaneous infection with virulent but not avirulent organisms. J. Immunol. 166, 1921-1929.

Titus, R.G., Marchand, M., Boon, T., Louis, J.A., 1985. A limiting dilution assay for quantifying Leishmania major in tissues of infected mice. Parasite Immunol. 7, 545-555.
Toledo, V.P., Mayrink, W., Gollob, K.J., Oliveira, M.A., Costa, C.A., Genaro, O., Pinto, J.A., Afonso, L.C., 2001. Immunochemotherapy in American cutaneous leishmaniasis: immunological aspects before and after treatment. Mem. Inst. Oswaldo Cruz 96, 89-98.

Wilson, M.E., 1993. Leishmaniasis. Curr. Opin. Infect. Dis. 6, 331-340.

Wilson, M.E., Weinstock, J.V., 1996. Hepatic granulomas in murine visceral leishmaniasis caused by Leishmania chagasi. Methods 9, 248-254.

Wilson, M.E., Young, B.M., Davidson, B.L., Mente, K.A., McGowan, S.E., 1998. The importance of TGF-beta in murine visceral leishmaniasis. J. Immunol. 161, 6148-6155. 